\title{
CEUP PIC
}

\section{CENTRO UNIVERSITÁRIO DE BRASÍLIA - CEUB}

PROGRAMA DE INICIAÇÃO CIENTÍFICA

Rafael Oliveira de Carvalho Mendes

Subjetividade social da família inserida no cuidado de parentes diagnosticados com Alzheimer

BRASÍLIA 


\section{CEUP PIC}

Rafael Oliveira de Carvalho Mendes

Subjetividade social da família inserida no cuidado de parentes diagnosticados com Alzheimer

Relatório final de pesquisa de Iniciação

Científica apresentado à Assessoria de Pós-Graduação e Pesquisa.

Orientação: Dra. Valéria Deusdará Mori

\section{BRASÍLIA}




\section{DEDICATÓRIA}

Dedico esse trabalho à minha mãe e ao meu pai, que sempre se desdobram para além do possível em busca da possibilidade de seus filhos trilharem seus próprios caminhos. 


\section{AGRADECIMENTOS}

Agradeço em primeiro lugar, minha orientadora e professora, Dra. Valéria Deusdará Mori, por em uma conversa de corredor ter aceitado e viabilizado o meu primeiro passo em uma jornada acadêmica, na qual sonho desde criança. Obrigado pela paciência, tempo e acima de tudo por promover um pensamento autoral e reflexivo.

Agradeço imensamente à Yonara e ao Clóvis, por se dedicarem na promoção de tudo que há de melhor para mim em todos os campos possíveis. Me orientaram, cobraram, ensinaram e amaram.

Um agradecimento também à Lumie que sempre está tornando minhas experiências de vida únicas ao seu lado.

Um agradecimento também à minhas grandes amigas e amigo, Ana Paula, Luisa e Roberto, que encontrei ao longo desse percurso, que sempre me acalmam e alegram compartilhando dos mesmos problemas, indignações, conquistas e rindo daquilo que não tem graça. 


\section{RESUMO}

Esta pesquisa buscou compreender os diversos processos subjetivos produzidos por um cuidador familiar de uma pessoa diagnosticada com Alzheimer, tendo como base a teoria da subjetividade desenvolvida por González Rey. Por conta dos objetivos desta pesquisa, foi utilizado o método construtivo-interpretativo, apoiando-se na Epistemologia Qualitativo de González Rey, buscando uma produção singular e dialógica. Participaram desta pesquisa uma mulher de 74 anos e um homem de 69, sendo ambos cuidadores de seus respectivos cônjuges. Foram realizados três encontros, com cerca de uma hora cada encontro, sendo realizadas dinâmicas conversacionais em todas elas. Por meio da dinâmica conversacional e orientado pela teoria da subjetividade, o trabalho viabilizou uma elaboração de hipótese na qual discute a importância do diagnóstico e a saúde do cuidador familiar.

Palavras-chave: Cuidador familiar, subjetividade, Alzheimer. 
SUMÁRIO

1 INTRODUÇÃO

2 FUNDAMENTAÇÃO TEÓRICA 9

3 MÉTODO 12

4 RESULTADOS E DISCUSSÃO 16

5 CONSIDERAÇÕES FINAIS

REFERÊNCIAS

ANEXOS 39 


\section{INTRODUÇÃO}

Dentro das práticas da psicologia a questão da saúde se faz presente em diversos momentos e é entendida a partir de mais de uma perspectiva, muitas vezes no meio médico, modelo vigente, deixando a pessoa que vive a experiência de lado e assumindo uma perspectiva onde a doença e o fim dos sintomas recebem maior atenção, assumindo um caráter patologizante de maneira determinista ao processo vivenciado pelo indivíduo.

As doenças crônicas degenerativas estão presentes na modernidade com uma maior intensidade e dado o caráter debilitador, que muitas dessas doenças apresentam, a presença de pessoas que assumem o papel de cuidador(a). Essa posição, muitas vezes ocupada por algum familiar, ofuscada pela própria situação vivida pela pessoa a qual é cuidada, pois sua condição já é entendida como uma experiência mais valiosa para compreender as questões do adoecimento.

A experiência vivenciada por algum familiar pode estabelecer uma compreensão única a respeito da vivência de estar presente com um parente em uma situação possibilitar compreender como algumas relações que se estabelecem e como elas são elaboradas ao longo do tempo.Neste artigo, propomos uma discussão com base na teoria da subjetividade no sentido de pensar como esses processos subjetivado,que não se esgota na experiência individual, são constituídos pela pessoa.As doenças degenerativas são atualmente responsáveis por mais da metade das mortes do mundo, sendo a doença de Alzheimer a mais presente entre os idosos.

\section{Justificativa}

O Brasil até 2025 se tornará o $6^{\circ}$ país com a maior população idosa, consequentemente o número de casos tende a acompanhar o crescimento desse grupo populacional, o que por sua vez aumentará o número de pessoas que irão desenvolver o papel de cuidador(a). A experiência de cuidador(a) necessita que haja uma reestruturação de vida, podendo afetar 
questões psicológicas e físicas. A pesquisa possibilita com que essas pessoas ganhem visibilidade que é perdida diante da situação de adoecimento de alguma pessoa próxima, e possibilitar por meio de sua expressão um compreendimento da experiência e possivelmente uma elaboração teórica desta situação.

Esta pesquisa buscou compreender os diferentes processos da subjetividade social de uma família ao cuidar de um parente que tem diagnóstico de Alzheimer.

\section{FUNDAMENTAÇÃO TEÓRICA}

O avanço tecnológico e científico aplicado à área da saúde proporcionou um aumento na expectativa e na qualidade de vida da população, diminuindo a mortalidade relacionada às doenças transmissíveis, por meio de medicamentos que inibem ou controlam a propagação da doença. Esse aumento na longevidade da população criou condições para que um maior número de pessoas venham a desenvolver doenças crônicas degenerativas não transmissíveis (DCDNT), sendo estas as principais causas de morte e incapacitação no Brasil, tomando o lugar das doenças infecciosas, que até o século XIX eram as principais causas de morte, acometendo mais de $50 \%$ da população brasileira, entretanto as diversas condições que são encontradas pela extensão do território brasileiro fazem com que haja um cenário em que ambos os tipos de doenças, transmissíveis (DT) e doenças crônicas não transmissíveis (DCNT) sejam um problema ainda presente. (Martins, Mendes, França, Dias, Kimura, Miako,1996). Em 2007 cerca de 72\% das mortes no Brasil foram atribuídas às DCDNT, mantendo uma tendência de crescimento deste valor com o passar dos anos.(Schmidt,Duncan, Silva, Menezes, Monteiro, Barreto,Chor, Menezes, 2011). Em 2010, cerca de 73,9\% das mortes foram em decorrência de algumas DCDNT (GVE,SUVISA, SES-GO, 2016)

A doença de Alzheimer (DA) é uma doença crônica degenerativa não transmissível e dentre esse tipo de doença a DA é a que prevalece na população idosa. Classificada como uma doença neurodegenerativa insidiosa e progressiva que é diagnosticada clinicamente pelo comprometimento da cognição e aparecimento de sintomas comportamentais, sintomas esses resultados de atrofia cerebral, morte neuronal, comprometimento do hipocampo e do córtex cerebral. Esses sintomas impedem a aquisição de memórias recentes, consolidação de 
memórias de longo prazo, problemas na linguagem, disfunções executivas nas habilidades visuo-espaciais. Esses sintomas preenchem as características satisfatórias para que seja dado um diagnóstico de DA provável, sendo o diagnóstico definitivo dado apenas após a realização de um exame anatomopatológico (Caramelli \& Barbosa, 2002). DA é caracterizada como demência, um conceito que abarca certos sintomas de diversas doenças caracterizadas clinicamente (Lima, Tatiane Machado, Brandão, Lenisa, Parente,Maria Alice de Mattos Pimenta, \& Peña-Casanova, Jordi.,2014) pelo início lento dos déficits de memória acompanhado por alterações de personalidade e declínio do quadro do paciente, afetando as funções do indivíduo, a qualidade de vida, o desenvolvimento econômico social e familiar.

O sintoma inicial desta doença é o déficit da memória episódica anterógrada que trata da dificuldade de recordar eventos recentes no tempo e no espaço (Charchat, Nitrini, Caramelli, \& Sameshima, 2001). Dado o fato do primeiro e mais evidente sintoma ser semelhantes a algumas características associadas à condição do envelhecimento, como a dificuldades para resgatar memórias é comum que haja uma demora pela busca de auxílio profissional, tanto por parte dos familiares quanto pelos próprios idosos.

Por se tratar de uma doença crônica é esperado que com o passar do tempo os sintomas se intensifiquem e que novos surjam, e devido esses fator, aquelas pessoas que vivenciam essa condição passam a necessitar do auxílio de outras pessoas para práticas diárias e de pessoas que cuidem deles, muitas vezes sendo essas as mesmas. Esse trabalho de ajuda e cuidado pode ser realizado pela própria família, por profissionais e por instituições de saúde.

Dentro da célula familiar a função de cuidador ou de cuidadora é comumente atribuída de maneira informal, onde a pessoa que a família percebe ser a melhor opção ou a de maior convivência acaba assumindo esse papel. Apesar deste processo de designação ter um carácter que está ligado diretamente a dinâmica da família, esse processo aparenta seguir certos padrões entre as famílias, obedecendo quatro fatores, sendo eles: o parentesco; o gênero, a proximidade geográfica e a afinidade afetiva. Além desses serem fatores que tendem a aparecer na discussão de quem assumirá os cuidados, essas categorias já apresentam um padrão mais frequente de pessoas às quais os servem, sendo o fator parentesco normalmente ocupado pela filha e cônjuge e o gênero escolhido e prevalentemente feminino. 
Apesar desses fatores surgirem outros como a disposição de tempo, a facilidade para lidar com situações esperadas, condição financeira e a expectativa de outros parentes em relação a quem deveria assumir o papel de cuidador também são levantados em conta. As dificuldades físicas não são as únicas que fazem parte do processo dos cuidados, há também as de ordem psicológica, como a apatia, tristeza crônica e depressão, sendo comum problemas financeiros ao longo dos cuidados financeiros (Teel \& Carson, 2003; Winslow, 2003). Sendo também identificado que cuidadores familiares de parente com Alzheimer, tendem a desenvolverem transtornos, como os citados e também, distúrbios alimentares, insônia, hipertensão e diabetes, com mais facilidade do que cuidadores de outros tipos de DCSNTs. (Delfino, Komatsu, Komatsu, Neri, Cachioni, 2021)

A experiência do Alzheimer vivenciada por um único parente de maneira direta afeta mais pessoas para além desse indivíduo, sendo recorrente a alteração das funções familiares; por exemplo, a filha ou o filho acabam assumindo o papel de zelar e monitorar seus próprios pais, ou parentes mais velhos, função essa que ao longo de uma vida foi realizada de maneira inversa (Ministério da Saúde, 2008). A literatura indica que dentro desse contexto a função de cuidar, além de ser atribuída normalmente as mulheres, elas apresentam um maior envolvimento.

O termo doença deixou de ser compreendido como um conjunto de sintomas característicos, e tem se definido como comportamentos que fogem de uma normalidade estatística da população, por conta deste enquadramento de comportamentos e generalização das condições de cada pessoa, esse entendimento de adoecer acaba que reduz a indivíduo e toda a complexidade que existe ao redor dele, desconsiderando a voz do indivíduo em relação a sua experiência de viver o adoecer. Na teoria da subjetividade, a compreensão da saúde está relacionada aos processos sociais e individuais, não podendo assim dissociar a pessoa de fatores históricos, culturais, sociais, individuais e sociais. Em contraponto ao modelo vigente, na teoria da subjetividade González Rey apresenta saúde como "qualidade dos processos de vida", sendo uma representação do desenvolvimento humano, ou seja, a saúde é um sistema complexo de sentidos que abrem possibilidades de escolhas para que a pessoa possa agir e se desenvolver. 
A saúde é configurada pelos sentidos subjetivos das pessoas, categoria elaborada por González Rey (2005). Esta categoria é entendida como uma produção única e singular da pessoa na sua relação com o mundo, onde o simbólico e o emocional operam juntos de maneira indissociável, organizada pelas representações subjetivas da pessoa em relação ao mundo, às suas vivências e seu contexto histórico e cultural, onde as representações simbólico são formada. (Mori, 2012).

Tendo esse como conceito de saúde é inviável que algo que abarca tamanha complexidade seja concebida por meio de uma perspectiva mecanicista do modelo biomédico considerando uma padronização de características puramente descritivas. elaborado a partir dos sentidos subjetivos que são produzidos pelos sujeitos individual e social, sentidos Nessa perspectiva, saúde deixa de ser uma categoria determinante, em que alguém é ou não é saudável, e passa a ser entendida como um processo em que a pessoa por meio da sua subjetividade consiga produzir novos sentidos subjetivos na sua relação com o mundo.

A condição que a doença gera à pessoa pode acarretar limitações qualitativas em diferentes áreas da vida da pessoa, sendo necessário o auxílio de amigos e familiares ao viver essa experiência. Do mesmo modo que a doença provoca uma nova dinâmica na vida do sujeito ela também afeta os demais que fazem parte desse sistema e havendo uma nova produção de sentidos por eles, de maneira que corresponda às representações simbólicas de cada um que são afetadas também pela posição ocupada na família, tendo em foco aqui a subjetividade. A subjetividade é uma categoria, compreendida neste artigo, que não se limita a fenômenos individuais e intrapsíquicos, sendo o resultado da relação de duas categorias, o social e individual, que fazem parte deste fenômeno. (González Rey, 2003).

\section{MÉTODO}

O intuito desta pesquisa é estudar os processos da subjetividade e a maneira a qual eles se organizam, necessita de uma epistemologia que seja capaz de contemplar a complexidade da produção de sentidos subjetivos que estão relacionados a contextos diversos de produção, uma base epistemológica e metodológica que abarque essas questões em conformidade a Teoria da Subjetividade, deve ser optada. Tais processos subjetivos também serão articulados com a ideia de saúde. 
Tendo em vista essas questões, o trabalho se desenvolverá a partir da epistemologia qualitativa proposta por González Rey $(1997,1999)$ que entende o conhecimento na pesquisa como uma produção construtiva interpretativa. Tal abordagem procura valorizar mais as questões qualitativas em relação à subjetividade do objeto estudado. Dada a condição histórica como as ciências, inclusive a psicologia, foram enraizadas no contexto americano, uma desconstrução foi necessária para que até mesmo a epistemologia qualitativa possibilita um estudo mais profundo dos fenômenos subjetivos.

Com o intuito de contemplar a as dimensões das produções subjetivas e as caracterizações reflexivas da produção de conhecimento, questões essas que o método escolhido abordará com maior qualidade, foi necessário uma reestruturação epistemológica responsável pela retomada do caráter reflexivo.

A epistemologia qualitativa está ligada de maneira indissociável à ideia de subjetividade, juntamente ao método construtivo-interpretativo ambas surgem como uma opção crítica para a prática e pesquisa em psicologia, num momento onde o construcionismo social e as interpretações críticas norte-americanas em relação à psicologia soviética, estavam presentes.

Existem três princípios, os quais a epistemologia qualitativa toma como base, conforme se segue:

1. Caráter construtivo interpretativo do conhecimento (González Rey, 2005, p.6) entende que o conhecimento é produzido pelas interpretações do ser humano, ou seja, o conhecimento é um processo construtivo-interpretativo. A interpretação produzida nesse contato não é livre por completa, apesar de, o pesquisador desenvolver as suas ideias a partir de suas reflexões, ele é orientado por uma teoria ao longo do processo interpretativo. Pesquisas que utilizam deste modelo não se esgotam, produzem questões que podem ser pensadas teoricamente. A pesquisa de caráter construtivo-interpretativo entende a prática do pesquisador como uma atividade simultaneamente teórica e dialógica. Sendo que a dialogicidade permite que a conversação se configure à medida que a pesquisa avança, dando vazão às subjetividades, não apenas do participante, mas também do próprio pesquisador, a qual ampara sua produção teórica. A subjetividade do pesquisador ganha um papel crucial que é orientar o processo de construção da pesquisa, juntamente com a 
criatividade, a qual sem ela, não seria possível que o pesquisador interpretar e configurar um significado a partir da subjetividade do participante que emerge no processo conversacional.

2.A singularidade tem uma posição fundamental para a produção científica, a qual não se trata de uma fonte exclusiva, mas sim de fonte única de informação que permite ao pesquisador, por meio de uma teoria, produzir conhecimento. A produção de um conhecimento legítimo e bem construído se dá a partir da qualidade da expressão dos indivíduos pesquisados, ou seja, a forma como as questões subjetivas emergem no diálogo têm mais importância para a legitimação do conhecimento construído a partir do método qualitativo do que a quantidade de envolvidos na pesquisa em si, e é justamente a qualidade da expressão do participante no processo de pesquisa que possibilita gerar modelos teóricos. A subjetividade do indivíduo é singular referente a sua constituição de sua história de vida e como ela foi interpretada, é justamente pela subjetividade ter essa característica de ser singular e referente a um indivíduo que possibilita uma representação abrangente às diversas configurações subjetivas de um problema, a qual nos permite estudar as dimensões subjetivas produzidas a partir desse problema

3. A dialogicidade ou integração traz a noção de que o conhecimento é produzido por meio da interação entre o pesquisador e o participante, por meio do diálogo, o qual estabelece um valor que vai para além da fala diretamente expressa pela pessoa, a maneira como ele é produzido carrega muito sentido. A dialogicidade na teoria da subjetividade é a maneira como o diálogo se configura como processo subjetivo. Onde surge a possibilidade do participante ser provocado a ponto de ser mobilizado e se manifestar de maneira espontânea, permitindo um desdobramento das questões qualitativas que surgem no diálogo, assim abrindo espaço para as configurações subjetivas (González Rey, 2017).

Este princípio do método epistemológico proposto, permite que a pessoa e sua singularidade ganhe uma maior visibilidade e valor no processo de pesquisa, sendo a fala da pessoa reconhecida por carregarem um nível de expressão e informação que vão para além das palavras proferidas, pois eles são produzidos por indivíduos mobilizados subjetivamente no diálogo. O diálogo não é um processo rígido, ele permite que a pessoa consiga se expressar com mais liberdade, não sendo delimitada por perguntas fechadas que orientam e limitam as respostas. Essa característica do espaço dialógico pode ocasionar momentos inesperados, os 
quais a conversa pode distanciar do tema que o pesquisador busca trabalhar, a expressão pode não ser de qualidade. A expressão da pessoa ganha maior qualidade à medida que elas são mobilizadas pelo tema e se sentem confortáveis em fazer parte desse processo, esse envolvimento proporcionado pelo pesquisador permite que uma maior qualidade na fala do participante, que por sua vez permite que o pesquisador trabalhe a partir disso, interpretando o que foi dito.

\section{Cenário de pesquisa}

A proposta do trabalho mobilizou algumas pessoas próximas que vivenciaram a experiência, que a pesquisa pretende estudar, a ponte de se oferecerem como participantes. Dois participantes, de famílias distintas, se voluntariaram, e em cada caso a pessoa ocupa uma posição diferente na célula familiar.

\section{Instrumento}

O instrumento é um meio que opera de modo dinâmico pelo o qual o pesquisador utiliza para mobilizar e acessar as excreções do participante no contexto de pesquisa. Tendo em vista o objeto que esta pesquisa pretende estudar, a configuração subjetiva de parentes de pessoas que vivem a experiência do Alzheimer, é necessário um instrumento que contemple a subjetividade das pessoas, de modo que as expressões dos participantes não sejam limitadas.

Para que isso seja possível a pesquisa pretende utilizar a dinâmica conversacional como instrumento, pois este sistema permite maior liberdade na expressão do sujeito, que é de crucial importância para que sua subjetividade seja alcançada com qualidade, indo de oposto à uma epistemologia que coloca o pesquisador em uma posição distanciada do participante, num discurso onde questões pré estabelecidas são expostas para o participante, modelo o qual pré determina a interação, logo a resposta, entre o participante e pesquisador.

\section{Participante}

Sandra, 74 anos, 51 anos de casada com R, 80 anos. Mora com apenas seu marido, entretanto tem quatro cuidadoras com ela, sendo que duas trabalham no turno do dia e duas no turno da noite. A filha mais nova e o genro se fazem constantemente presentes para 
auxiliar no possível. Dona S passou a perceber comportamentos diferentes em seu marido no início dos anos oitenta, entretanto o diagnóstico de Alzheimer veio apenas em 2006.

Dona S sofre de artrite e artrose o que dificulta significativamente seu deslocamento e certas atividades.

O Senhor Renato, de 69 anos, é casado com a senhora Marilda de 65 anos, e estão juntos há 44 anos. Na casa a qual ambos moram, também é frequentada diariamente por mais duas enfermeiras. Renato afirma que uma colega de sua esposa foi a primeira pessoa a reparar algumas dificuldades motoras. Neste período, a senhora Marilda estava com 35 anos.

\section{Análise e construção de informação}

Nessa metodologia (González Rey, 2005), a análise e construção de informação é orientada a partir dos indicadores que são peças de informações produzidas pelo pesquisador a partir da fala das pessoas,ou seja, é um produto do pesquisador, não estando implícitas nas expressões do participante. Os indicadores são os primeiros significados elaborados pelo pesquisador sobre as questões as quais o interessam e são o ponto inicial para o desenvolvimento da pesquisa, estando presente do início ao fim. A partir de um conjunto de indicadores uma hipótese se estabelece, e apesar de ainda estar em um nível hipotético está elaboração do pesquisador já passa a estabelecer uma relação com os modelos teóricos.

\section{RESULTADOS E DISCUSSÃO}

\section{A caracterização da participante}

Dona Sandra, 74 anos, 51 anos de casada com R, 80 anos. Mora com apenas seu marido, entretanto tem quatro cuidadoras com ela, sendo que duas trabalham no turno do dia e duas no turno da noite. A filha mais nova e o genro se fazem constantemente presentes para auxiliar no possível. Dona S passou a perceber comportamentos diferentes em seu marido no início dos anos oitenta, entretanto o diagnóstico de Alzheimer veio apenas em 2006.

Dona S sofre de artrite e artrose o que dificulta significativamente seu deslocamento e atividades de lazer. 
O recorte da dinâmica conversacional a seguir se refere ao período até o diagnóstico de Alzheimer.

Rafael (R): A senhora lembra quando foi que começou a cuidar dele? Quando ele foi diagnosticado?

Sandra (S): "Lembro... lembro. Foi um começo muito difícil, porque a gente não entendia, íamos aos médicos e ninguém sabia, a gente fez 26 exames. Ele começou a mudar o comportamento. Às vezes ia comprar alguma coisa, trazia outra, aí ele ia... sabe? Não dava para entender. Fazia tomografia, ia ao neurologista, não dava nada, graças a deus, mas vivia com dor de cabeça" "Aí um dia eu troquei, fui num geriatra, depois de vinte e poucos anos, faz muito tempo que ele não tá bem".

"As tomografias, as ressonâncias não davam em nada, e eu levei ele num geriatra. Ele mandou ele para uma psicóloga, amiga dele lá, e disse: Isso aí é um Alzheimer, mas vai na psicóloga para confirmarmos, mas eu não tenho dúvida.

Eu achei estranho. Assim... Só dele olhar e falar com o Rodrigo e ele saber. Eu fui fazer o exame e não deu outra, para você ver que loucura, a psicologia muda muito."

Neste momento é possível perceber a perplexidade de Sandra ao ouvir o geriatra afirmando que era Alzheimer, tendo em vista o número de médicos pelos que passaram e a quantidade de exames feitos ao longo de duas décadas. Ao descrever essa cena ela demonstrava ainda certo espanto com a descrição do médico. Logo em seguida a participante relata a reação de seu marido no momento em que o geriatra se dirige a ele e repete o diagnóstico.

S: Aí ele falou assim: O senhor tá com Alzheimer.

Ele nem ligou! Ele já tava tão avançado que para ele tanto fala uma coisa quanto outra, mas ele ainda andava e conversava, mas já andava com 
secretaria. As vezes descia na portaria e não conseguia subir de volta para o apartamento. Aí tivemos que contratar alguém para andar com ele.

Ele nunca me falou nada! Ele nunca me disse algo assim: Ou... vamos lá no cartório? Arrumar os papéis porque depois eu não vou ter jeito de assinar. Mas para ele foi como se nada tivesse acontecido, é o trem mais engraçado, foi aos poucos, foi acabando aos poucos. Ele foi acabando aos poucos.

É..., mas o Alzheimer é muito triste. Eu só sofri muito até descobrir o que era. o Engraçado é que não acusava nos exames, isso que era engraçado.

No momento em que a participante descreve a falta de reação de seu marido, sua emocionalidade emerge de modo que sua fala ganha um tom mais enfático, carregando indignação e raiva ao falar da maneira a qual o seu marido reagiu ao diagnóstico. Já de imediato, Dona Sandra (S) explicou que seu marido já não estava em condições de discriminar determinados estímulos, o que aponta uma contradição, mesmo tendo consciência da condição de seu marido ela demonstra raiva pela falta de reação dele. $A$ existência dessa contradição pode indicar a maneira a qual a participante compreendia seu marido e um possível indicador da relação deste casal.

A fase seguinte destaca um comportamento que seu marido deixou de tomar durante um período após ouvir o diagnóstico. As falas escolhidas por $\mathrm{S}$ ilustravam muito mais um comportamento desejado por ela, demonstrando que havia uma expectativa com as atitudes de seu marido. Cabe destacar novamente a contradição existente em sua fala. A frase anterior à que manifesta seu desejo, ela descreve a incapacidade de seu marido de reagir a estímulos distintos, mas mantém a expectativa de que ele seja capaz de tomar uma iniciativa para qualquer tipo de assunto o qual ele seria "protagonista", mantendo o papel de provedor e administrador da família.

O que cabe pensar na existência de mais um indicador sobre a relação deste casal, em que o marido assumia um papel de protagonista, tomando as iniciativas para com a família.

S: E aí ele broncoaspirou, aí tivemos que colocar a sonda nele. Eu fiquei 19 dias com ele no hospital, para me acompanhar. Ele tá até hoje. Ele já não toma 
mais banho no chuveiro, ele não consegue, ele embola sabe? Ele vira uma bolinha.

Faz muitos exercícios com a fisioterapeuta, fono também.

Ele não entende nada, parece que não, porque você chama ele e ele nem... Um morto vivo, parece um morto vivo. E é isso aí... de vez em quando vem uma febre, de vez em quando vem uma infecção de rim...

O alzheimer na verdade não mata né? São as doenças que ele acarreta que vai matar.

O cardiologista nosso disse: Nós vamos preparar ele, vamos pelo menos cercar o coração dele para ele não morrer. Aí colocou os stents, ele tem 3. Ai é assim, dá remédio, o médico vem, e ta ai... dorme, acorda, não fala nada, mas dorme muito bem, não precisa de remédio para dormir. Quando ele quer alguma coisa, quando tá muito quente ou muito frio, ele começa a tossir.

Quando ele quer alguma coisa, quando tá muito quente ou muito frio, ele começa a tossir.

R: Ele tosse? Entendi.

S: É a maneira dele se comunicar. É engraçado né? Parece que a gente já conhece. Parece menino, ele vai tentando a gente vai mexendo em tudo e depois cala a boca e vai dormir. (rindo)

Algo que surge com certa frequência na fala da participante são termos que distanciam de uma posição de autonomia e até mesmo de características humanas do seu marido, havendo uma desumanização dele. Adjetivos que o caracterizam como uma "bolinha", um "morto vivo". No momento que ela relata que passou um período no hospital acompanhando seu marido e afirma que ele ainda está no hospital, mesmo tendo voltado para casa com ela a mais de 10 anos. A participante está assumindo que saiu do hospital com uma outra pessoa, o marido ficou no hospital. Essa frase pode ser um indicador da maneira como Sandra 
produz com relação a seu marido, no caso, a participante considera que o marido que estava com ela antes dele ser internado não existe mais.

Esse momento da hospitalização foi um momento marcante que estabelece um ponto simbólico da perda de seu companheiro, o qual tinha uma configuração subjetiva.

A decepção, raiva e frustração com a falta de iniciativa do cônjuge descrita no trecho anterior pode estar associada ao fato do marido já não se encaixar nos sentidos subjetivos os quais ela produziu ao longo de anos não corresponde mais a pessoa que está com ela, o sentido subjetivo e a sua configuração subjetiva colocam o seu marido em uma posição de sujeito a qual ele não exerce mais, o que acaba criando expectativas que não serão correspondidas.

A raiva e a frustração ainda existem com relação ao marido, que tomava as iniciativas e ocupava um papel fundamental na dinâmica familiar, pois os sentidos subjetivos da participante que se referem ao marido não são compatíveis com a pessoa que ele é atualmente, havendo uma quebra de expectativa.

A experiência do período de internação possibilitou com que uma nova produção de sentidos subjetivos ocorresse de modo que o marido passou a ser reconhecido de uma maneira distinta, apesar de também haver uma descontinuidade no que se refere em considerar o marido. Nesta nova produção, ele é tirado da posição de alguém apto, e é colocado em uma posição de objeto, que apenas reage aos estímulos primordiais e básicos, como dor, frio e febre. Mesmo não havendo um intuito direto em denegrir a pessoa, as palavras que emergem para descrever o marido, durante a dinâmica apontam como ela o compreende. Existe também uma infantilização do Rodrigo por parte da participante. Apesar do marido da dona Sandra está com o repertório comportamental restrito, e semelhante à uma jovem criança, o modo o qual ele é comparado faz com que ele seja afastado da sua real condição, mesmo não havendo uma intenção de denegri-lo de alguma forma.

Sandra tem artrite e isso faz com que algumas atividades sejam dificultadas.

S: Também, já não estou mais com tanta saúde. A minha filha está me ajudando muito. Eu já não faço mais mercado, porque me deu um problema sério na perna, tenho andado com as minhas duas bengalas. Aí eu só pego o carro para ir ao salão, para ir na casa dela. 
Porque já estou assim ... do meio dia para tarde. Nossa diferença é de cinco anos e oito meses. Eu sou mais nova que ela, mas a minha cabeça é de vinte anos só que o corpo de cem.

R: Estou percebendo. O tanto de detalhe que a senhora está falando, datas então.

S: (risos) É isso aí. (Rindo) Eu fico pensando: Ó meu Deus que vontade de sair, de andar. Eu amo ir nas lojas, comprar. Seriamente, até a portaria do meu prédio eu já não vou mais. Vai sumindo, a gente vai acabando aos poucos também. (Conformada/triste)

A maneira como ela percebe e descreve que seu corpo envelheceu e não consegue mais acompanhar os desejos e a rotina que ela tem, mostra como o corpo é uma questão que atrapalha o acesso dela às atividades que trazem prazer para ela. Dentro de uma rotina que ela descreve ser desgastante e que cobra da pessoa que está exercendo a função de cuidadora, o corpo pode estar sendo um empecilho para uma prática de saúde. A maneira como ela descreve a vontade de sair e fazer compras, utilizando uma expressão popular de maneira extremamente chamativa e pensa com frequência, é possível pensar que o sentido subjetivo de uma identidade esteja atrelada à realização dessas atividades. 0 corpo assume a função de ferramenta,o qual viabiliza o acesso às atividades que ela deseja, e como essa ferramenta já não funciona mais da maneira que satisfazia os desejos e as vontades, existe a perda de sua identidade.

A perna é um fator que está diretamente relacionado à configuração subjetiva de Sandra.

$R:$ A senhora comentou que às vezes tem esse desejo de sair. Que sente falta de sair...

S: Sinto. Sinto, mas a perna não tá boa, como é que anda? Tô falando a cabeça de 20 e o corpo de 100.

A perna foi para um lado e o pé foi para outro. Acabou o calcanhar. Eu até ia fazer a cirurgia, mas não dá para fazer igual o doutor falou. Por que meu pé não tem mais osso. 
O pé arretou por um lado e a perna para outro. É pisando com a perna e esse que é o problema. Eu não dou conta de andar dói demais da conta, mas a cabeça eu tenho vontade, né, meu filho?

Não é boa coisa, mas ainda bem que eu aproveitei muito a vida, sabe?

Ainda bem que eu aproveitei muita vida porque senão eu já estava em depressão, viu? Porque não é brincadeira não, ficar no apartamento direto, sair só esses pouquinhos não é fácil. E quando saio ainda tem essa dificuldade.

A vida dessa pessoa sofreu diversas alterações, do mesmo modo que existiu uma expectativa, um desejo com relação às atitudes de seu marido, a participante também tinha desejos com a própria vida. O adoecimento do marido colocou ela em uma posição a qual ela não desejava, distanciando ela de uma posição periférica de responsabilidades. As responsabilidades que antes eram atribuídas ao marido passaram a ser assumidas por ela.

O mal estar proporcionado pela perna atinge diversas facetas da vida de Sandra para além das dimensões da saúde física. A perda de mobilidade juntamente com as dores dificultam que ela tenha acesso à atividade que ela julga como prazerosa e atrapalhando também relações sociais e familiares. O modo o qual a participante expressa sua percepção com relação ao seu corpo e sua mente nos permite levantar um indicador das configurações subjetivas com relação a esta dinâmica, sendo o corpo um limitador para as atividades e relações que a mente do jovem deseja e ainda tem disposição. O modo como o corpo não tem condição física o suficiente para acompanhar a sua "mente", pode ser uma condição adoecedora para a participante.

S: Durante três meses eu não consegui pôr o meu pé no chão e eu pensei muito no meu marido. O meu maior é o meu marido.

É meio difícil no começo você aceitar essas coisas porque eu andava muito.

Você vê? Os aniversários dos meus netos, eu já não vou. Não vou na casa das minhas filhas. É muito difícil ir para a casa das minhas filhas, uma vez ou outra vamos natal com muita dificuldade. 
Porque ficar lá esperando o natal, a festa, você não sabe onde pôr a perna. Você tem que ficar mais deitada, mas sentada, não pode ficar muito tempo. É complicado porque dói muito, incha muito e a dor não é brincadeira... nossa senhora. Aí começou a pré diabete, mais remédio para isso.

A minha vida é essa, eu só vou levando. E peço a Deus para vencer essa etapa.

À medida que a participante explicita os problemas proporcionados pela perna é possível identificar novamente um indicador de que as relações familiares da participante são prejudicadas. A família é subjetiva de modo que ocupa uma função de alegria e por não estar sendo acessada pode ser adoecedor para a participante.

Algo que se destaca entre esse trecho e o anterior, sendo que este foi dito imediatamente após o anterior, é a contradição existente. No trecho anterior a participante se mostra satisfeita com a sua trajetória, demonstrando ser compreensiva e estar lidando bem com a situação todavia ela pede à Deus para que a auxilie a superar o momento pelo o qual está passando Essa contradição pode ser mais um indicador de como o os problemas na perna atrapalha a vida da participante.

S: Eu fico pensando: Ó meu Deus que vontade de sair, de andar. Eu amo ir nas lojas, comprar. Seriamente, até a portaria do meu prédio eu já não vou mais. Vai sumindo, a gente vai acabando aos poucos também.

Saudade de viver como dizem os outros. Ir em um mercado, ir em uma loja, porque eu não vou mais na loja, às vezes eu compro pela internet, mas não é tão bom assim não. Vai levando.

A felicidade foi muito marcante, isso sim. Se aprontar ir em uma festa, se aprontar e ir para uma loja comprar roupa, sapato, bolsa. Bolsa?Nem ando mais, e o medo de ladrão.

A maneira como essas falas surgem a todo momento ao longo da dinâmica, permite pensar que exista um valor significativo para todo esse conjunto de práticas de lazer, com destaque para as compras. A importância atribuída pela participante e a maneira que ela descreve 
essas práticas, dá a entender que são velhos hábitos que já não são mais realizados. O valor atribuído juntamente com a noção de velhos hábitos, faz com que um possível indicador de uma antiga dinâmica configuracional seja pensada. Outro indicador produzido a partir desta colocação, é o de que existem sentidos subjetivos que foram configurados, de modo que Sandra (S) ocupasse uma relação que ela não se distanciava de determinadas responsabilidades, e tinha como parte de sua rotina as práticas de lazer citadas que se tornaram identitárias para essa pessoa. Esta dinâmica de relação já configurada faz com que Sandra se frustre com a "ausência" de seu marido.

Ao longo da dinâmica conversacional, quando a participante descreveu o quanto a perna a impossibilita de determinadas práticas, indo de se mover de um cômodo para outro até visitar suas filhas. A participante comenta que buscou uma intervenção cirúrgica.

\section{S: Eu fui em quatro médicos, dois operavam e dois não operavam.}

E aí então eu falei que então eu também não vou operar não. Os médicos falavam: "Mais aonde eu vou colocar a peça aí? Sendo que a sua perna já não tem mais nem osso. Moeu tudo".

E para operar eu terei que mudar muita coisa na minha casa e eu ai eu nao iria ajudar. Toda a vida eu ajudei o meu marido. Aumentar os funcionários... Ahhh é uma novela.

Ele falou: Eu não tenho coragem de fazer uma cirurgia muito grande. É melhor a senhora aprender a viver desse jeito, com sapato especial...

A partir deste diálogo um novo indicador começou a ser formado. Este, por sua vez, está relacionado ao modo como Sandra é mobilizada para realizar seu autocuidado, estando diretamente relacionado aos sentidos subjetivos que produzem com relação ao seu marido.

Ao buscar uma intervenção cirúrgica a participante encontrou dois médicos, dentre quatro visitados, que negaram fazer o procedimento e orientaram a buscar maneiras de se adaptar e aprender a viver daquele modo. Estes mesmos médicos a informaram de como seria o período do pós operatórias e as mudanças que ela iria sofrer, sem contar nas possíveis complicações por conta da dificuldade, do tempo de cirurgia, da idade da paciente e da 
pandemia. Dona S. estava disposta a correr estes riscos em busca de recuperar parte de sua mobilidade e por consequência a vida que ela estava com "saudade", como ela disse.

O que a mobiliza a não realizar a cirurgia é o sentido subjetivo do cuidado com relação ao seu marido.

R: Como a senhora se sente em relação ao seu marido neste momento Dona S?

S: Eu me preocupava muito. Por isso que eu fui em vários médicos, fiz vários exames para ver se aprova ou não, porque se eu não tivesse o $R$ na minha vida, eu operava, de cara eu já iria operar.

Mas eu pensei: Coitado, ele precisa tanto de mim.

Os sentidos subjetivos do cuidado tem tamanha força de modo que a participante abre mão de realizar uma cirurgia que poderia recuperar parte das práticas que compõem os sentidos de saúde para ela. Tendo em vista que a participante sabe dos riscos e mesmo assim cogitou a fazer caso o marido não dependesse dela. Novamente emerge em sua fala que coloca o marido em uma posição de pena. Desta maneira, é possível perceber que existe uma ordem de importância e prioridade entre os sentidos subjetivos existentes, tendo isso em vista a função de cuidadora pode sim ocupar uma função significativa em sua configuração subjetiva, todavia isso não implica necessariamente em uma condição de saúde, mas possivelmente uma adoecedora.

S: Estou agora com umas marmitinhas aqui. Sem graça! Eu cozinhava costela, macarrão e isso eu já não como mais. Eu preparo para mim e para as funcionárias, se elas quiserem almoçar, mas só tem isso. O meu marido tem aquelas dietas.

Durante três meses eu não consegui pôr o meu pé no chão e eu pensei muito no meu marido. O meu maior é o meu marido.

Por que não é fácil, quando você acerta as funcionárias tá bom mas e enquanto você não acerta. É tanta coisinha, e graças a Deus está bem controlado. 
E o médico: "É melhor a senhora aprender a viver desse jeito, com sapato especial...".

O marido aparece novamente em uma posição de prioridade e ganha um ar de superioridade, ocupando um espaço de extrema admiração pela participante, algo que se destaca é novamente um indicador de que o auto cuidado é realizado para que ela consiga continuar cuidando do marido. A participante mudou seus hábitos para que consiga se manter à disposição do marido. Esse seria o principal indicador de que o sentido subjetivo do cuidado ocupa uma posição de destaque em sua configuração subjetiva, mesmo que " $\mathrm{O}$ cuidado manda muito".

No trecho a seguir a participante explica um pouco como foi assumir questões administrativas, que pertenciam a seu marido.

Eu troquei a fazenda para ficar mais fácil para mim, eu mudei todinha quando eu descobri que era o Alzheimer. Eu fiquei com funcionário da fazendo só por 3 anos, aí eu entreguei para o meu genro tomar conta.

Porque a fazenda não é coisa de mulher. E o povo pensava: Mulher mandando... E eu não preciso passar por isso não. Arrendei para o meu genro, ta tudo ótimo, tem 5 anos que não vou lá.

Nessa breve fala é possível perceber sentidos subjetivos com caracteres machistas. A maneira como ela configura a função social do homem interfere que ela ocupa em diversos momentos uma posição mais ativa, podendo produzir um sentido subjetivo de saúde. 0 homem, muitas vezes, aparece em suas falas como uma pessoa responsável por tomar decisões, as quais considera importantes, sempre sendo uma imagem de liderança e de controle. O sentido subjetivo social que configura a sua função a impede de assumir uma nova relação, criando uma dinâmica adoecendo, por ter que ocupar uma posição a qual ela não se reconhece, e sente raiva de seu marido por ele não realizar mais as funções que foram objetivadas por Sandra. 
R: A senhora comentou que de vez em quando pega o carro para passear naquele dia em que a senhora está mais estressada ou chateada com alguma coisa.

S: Você sabe que eu não me estresso tanto? Às vezes eu sinto saudade, a minha depressão é tipo assim ... saudade, de tudo eu tenho saudade. Aí eu já sei, vou lá e bebo meu remédio, às vezes eu saio e às vezes eu não saio.

\section{R: Saudade de que dona S?}

S: Porque quando meu filho morreu eu entrei em depressão, eu tomei remédio né. Então quando eu vejo que estou começando a sentir saudade, quando vai me dando uma vontade de chorar, eu vou e tomo meu remédio. Eu não quero chorar não, eu quero viver muito. Eu tenho é muita dó do meu marido, isso aí eu tenho muito, tem hora que a dor corta a gente e isso aí pesa. Ai eu vou e me desligo, porque não é fácil.

Eu acho assim, como eu estou andando, eu quero andar, eu quero né... Isso é muito doído, ele não ficava quieto, eu era uma pessoa toda preguiçosa, ele toda a vida trabalhou demais. É...essas coisas da vida (voz trêmula).

Ao abordar este assunto a emocionalidade da participante emerge de modo que fica claro que o tema é delicado para ela, enquanto ela falava sua voz ficava cada vez mais trêmula e aguda. Ela identifica a causa de seu estado melancólico como a saudade, logo a falta de algo que já vivenciou, entretanto cabe o pensamento que a saudade não seria exatamente a causadora de seu sofrimento, mas a maneira a qual a participante percebe o contraste entre o passado e o presente. Aqui aparece novamente o indicador que se refere à falta dos velhos hábitos e posições as quais ela tinha. A participante cita o filho falecido pela primeira vez, mas já havia expressado que o câncer, causa da morte do filho, é um sofrimento muito maior que o Alzheimer. É possível pensar que a participante não pretende entrar em contato com estas questões, tendo em vista a automedicação feita para se "desligar", é feita quando ela percebe que está começando a ficar melancólica. A participante não faz nenhum tipo de acompanhamento médico. 
Existe uma inconformidade na maneira como a participante compreende o fato dela se considerar preguiçosa, mas poder andar apesar das dificuldades, e o marido ter sido uma pessoa ativa a vida toda e agora não ser mais capaz de andar.

\section{Caracterização do participante}

O Senhor Gustavo (G), de 69 anos, é casado com a senhora Marilda de 65 anos, e têm 44 anos de casados. No apartamento no qual ambos moram, também é frequentada diariamente por mais duas enfermeiras. Gustavo afirma que uma colega de sua esposa foi a primeira pessoa a reparar algumas dificuldades motoras. Neste período, a senhora Marilda estava com 35 anos.

O recorte a seguir, trata de um momento da dinâmica conversacional, o qual trata do momento o qual os sintomas foram reconhecidos inicialmente até o diagnóstico.

R: O senhor lembra como foi que começou?

Gustavo (G): Foi assim. Ela fazia um trabalho voluntário e começou a não dar conta de dobrar aquelas pastas para guardar arquivos. E uma amiga dela me ligou falando: "Óh a, Dona Marilda não está bem. Não está dando conta de dobrar.

Ai dai... de 2007 para 2021 ela foi piorando gradativamente, então hoje ela não consegue comer, beber, fazer higiene pessoal, tomar banho andar, e a doença foi gradativamente debilitando.

R: Hum hum entendo. Durante esse período em que a doença foi se agravando, quais foram as medidas que o senhor tomou?

G: É questão de médico. Nós fomos à um neurologista, o nome do neurologista (...) e ele pediu uma série de exames e a gente não se conformou e fomos para o HC, lá em São Paulo. E lá em SP eles fizeram exames, um monte de exames de líquor, e eles puseram uma interrogação no Alzheimer.

R: Essa interrogação que colocaram foi o mesmo motivo da inconformação do senhor?

G: Não, mas eu não tive ainda um diagnóstico exato do que foi, mas juntamente com o que o primeiro médico falou é alzheimer, pensaram até que fosse parkinson atípico, inventaram um monte de coisa... 
R Mas como era a sensação de não ter um diagnóstico específico?

G: Ah! Era horrivel! Era horrivel! Porque a gente ficava pensando que se não fosse alzheimer, poderia ter alguma coisa para fazer.

Neste trecho existe um possível indicador com relação a percepção de um diagnóstico de Alzheimer. Existe uma percepção de que esse diagnóstico é de caráter condenatório, o que leva o participante a buscar mais uma bateria de exames em um hospital referência, que fica em um estado distinto do qual ele reside. Um ponto a ser destacado é a emocionalidade do Gustavo durante o período de espera por um diagnóstico, apresentando uma angústia, e uma ansiedade frente a possibilidade de uma diagnóstico distinto do de Alzheimer, reafirmando o indicador de uma produção subjetiva que atribui um caráter condenatório. Quando se fala em um diagnóstico, dentro de uma lógica biomédica uma das reflexões que surgem é a maneira como o diagnóstico pode atribuído de maneira tão íntima à uma pessoa ao ponto dela passar a se identificar e elaborar sentidos subjetivos a partir deste modo de se identificar, adoecido e unidimensional, sendo raso para explicar a complexidade e pluralidades dos fenômenos psicossociais humanos. Entretanto, nesta situação a ausência de um diagnóstico proporcionou um intenso momento de sofrimento para o cuidador, pois havia a esperança de não ser Alzheimer, que em sua compreensão é um sentença de que a sua esposa não iria melhorar, mas mesmo sendo Alzheimer, o participante deixou de ter esse sofrimento da dúvida e passou a agir para prover os cuidados necessários para sua esposa. Logo em seguida o participante interrompe o assunto e expressa tal fala:

Gustavo: Então, assim, parece que eu perdi a vontade de ter tudo, de tudo. Não tenho vontade de sair, de fazer as coisas. Parece que eu fiquei adormecido. Se eu sair, apesar dela ter duas cuidadoras, eu fico preocupado. Mas mesmo assim, para mim foi como se eu tivesse me afogando.

\section{R: Seria uma sensação de desespero?}

Seria mais um desânimo, um desânimo da vida.

Gustavo descreve como ele passou a se sentir após o diagnóstico e adoecimento de sua esposa. A partir desta fala dois indicadores podem ser elaborados, o primeiro com relação a 
sua esposa, sendo que esse se refere a um relação à qual ela passa a ocupar o centro de todas as suas demais atividades. O segundo indicador trata de um adoecimento, pois Gustavo não consegue produzir nos sentidos subjetivos para além desses, que já o acompanham a quase quinze anos.

Parece que fica um buraco na vida da gente.

\section{R: Nesse buraco. O senhor entende o que estaria faltando?}

Falta ela. Eu por exemplo. Eu sou muito convidado para passear. Esses tempos mesmo, um amigo meu, médico, ia casar a filha. Eu fui convidado, só 23 pessoas, para ir a Paris e só pagava a passagem.

Eu não queria ir, mas ele insistiu tanto que eu fui. Fiquei nove dias lá, mas nove dias de terror. Sabe como é que é?

Seria uma sensação parecida, mas mais intensa do que quando o senhor sai de casa.

Sim isso. Eu me senti como se estivesse traindo

Por meio desse diálogo é possível identificar novamente o indicador da prioridade que sua esposa tem. A maneira como ele se refere ao buraco em sua vida, nos permite pensar que houveram novas produções subjetivas com relação a sua esposa, entretanto o buraco, a falta se refere à uma necessidade que não foi satisfeita por esses novos sentidos subjetivos, juntamente pela nova dinâmica relacional.Os novos sentidos subjetivos com relação a esposa não entram em conflito com os antigos. Ao passo que ela adoecia novos sentidos subjetivos foram sendo produzidos, sendo que o sentido subjetivo que se refere a esposa adoecida faz com que ele tenha um comportamento com foco no zelo, que ele mude as prioridades, que ele produza novos sentidos subjetivos sociais com relação ao casamento. Essa nova realidade que se apresentou a ele, fez com que ele buscasse maneiras de lidar com questões que surgiram, algumas sendo expressões de saúde e outras do adoecimento.

Neste momento em especial da dinâmica, indicadores de sentidos subjetivos que se referem ao casamento e seus deveres morais e éticos surgem na fala de Gustavo, e novamente o indicador de um sentido subjetivo o que prioriza sua esposa. A noção matrimonial do participante é fortemente composta por um senso de fidelidade e companheirismo. Os sentidos subjetivos sociais do casamento são formados por uma herança cultural judaica 
cristã, ambos os cônjuges estarão acompanhando o caminho dos outros apesar das enfermidades.

Rafael: Traição no sentido de cuidado, de que o senhor deveria estar com ela?

Sim. Eu deveria estar com ela.

Rafael: O senhor poderia falar mais um pouco sobre essa sensação de traição, o porquê o senhor acha que ela surja.

Assim... eu penso assim, ela está lá presa na cama e eu to aqui querendo curtir. Então eu acho isso bem ruim, bem ruim. Porque a gente era muito ligado, sabe? Então é isso que eu te falo. Eu fiquei um pouco debilitado, muito debilitado, muito debilitado mesmo.

O indicador do sentimento de traição aparece aqui novamente na explicação do participante, com relação aos prazeres da vida, essa configuração subjetiva muito provavelmente está sendo produzida a partir dos sentidos subjetivos sociais.

Os indicadores da subjetividade social do casamento e o indicador de sentido subjetivo da prioridade dada à esposa estão intimamente ligados. A traição citada se distingue por está relacionada ao fato dele ainda ser capaz de ter prazer com bens materiais, enquanto a esposa não, ferindo a noção de companheirismo. O nível de intimidade e união que ele descreve, e reforça como esse fator é extremamente significativo para ele e fazia parte da dinâmica familiar do casal, aponta que mesmo ele ainda podendo realizar certas atividades, isso seria de certa forma um uma traição com sua esposa, com a dinâmica a qual eles viveram. Aqui é possível identificar que Gustavo não foi capaz de produzir novos sentidos subjetivos com relação à dinâmica relacional e matrimonial quando se refere a esse tipo de união.

Gustavo sente falta da dinâmica que existia anteriormente ao adoecimento de dona Marilda, a maneira a qual ele começou a produzir subjetivamente a partir das dinâmicas de lazer faz com que elas tenham um caráter punitivo. A emocionalidade emerge de modos distintos dentro deste contexto de "traição", sendo uma delas a por conta de não estar fisicamente 
próximo a sua esposa, surgindo uma ansiedade, e quando a atividade está relacionada com o desfrutar da vida, emergindo uma angústia. Ambas as emoções podem surgir juntas.

Neste momento Gustavo fala sobre uma dinâmica familiar que iniciou juntamente à pandemia.

Apesar da meiguice dela, da concordância dela, a gente ficou muito... não sei...

Perdeu o senso de família. Apesar de eu fazer tudo agora fica assim: $A H$ vamos fazer isso - Não. não compensa.

É uma sensação horrível, não é boa não.

Rafael: Quando existe essa discussão que alguém fala que não compensa. Qual seria a discussão em pauta?

Aqui em casa, a casa é muito grande, são dois pavimentos e a sala tem 75 metros. Eu dei os meus móveis tudo. Se vocês quiserem, vocês pegam. Parece que deu um baque na minha vida.

Rafael: Os seus filhos ainda mantêm contato? Sei que na pandemia fica mais difícil.

Sim eles matem. estão tudo de quarentena os dois.

A família continua unida de acordo com o participante, mas a maneira a qual ele tem produzido com relação aos seus filhos está sendo atravessada por sentidos subjetivos os quais o colocam em uma posição a qual tudo deve ser feito em pró da sua esposa. O pai, Gustavo, ao buscar promover todos os tipos de recursos para promover o bem estar de sua esposa, se considera a pessoa que está mantendo o senso de união da família, dos laços. Mas os filhos reconhecem que alguns atos do pai não são condizentes, como se desfazer dos móveis ou gastar com certos procedimentos com a mãe, sabendo, por orientação médica, que não surtirá efeito ou que seria melhor deixar a mãe descansando em casa O indicador da traição surge aqui em também, mas de uma forma distinta das anteriormente citadas. O participante se desfez de boa parte de seus móveis, seguida a lógica de que ele se sente culpado por estar desfrutando de seus bens sendo que sua esposa não pode mais fazer o mesmo. 
Foi. Foi junto a pandemia que me deu esse estranho de não querer as coisas mais. Não querer isso, não querer aquilo. "Não! Não quero isso não. Isso é supérfluo"

Rafael: Quando o senhor se refere a alguma coisa ser supérflua o que te faz julgar uma coisa a ser supérflua?

Por exemplo, eu tinha uns 20 quadros do Puteiro e eu dei tudo. "A não! Isso só serve para limpar". E foi assim... um desânimo mental de não querer bem material. De que adianta eu ter bem material,eu ter algum dinheiro se eu não posso fazer nada? Se entendeu?

Do mesmo modo o qual o participante atribuiu um sentido subjetivo de traição ao desfrutar das práticas de lazer, as quais ele e sua esposa tinham juntos, é possível supor que a nova dinâmica organizada pela pandemia, fez com que o participante passasse mais tempo em casa, usufruindo com maior frequência de seu lar. Com a restrição de atividades fora, o ambiente residencial se tornou um meio de prazer, que ele usufruía e sua esposa não, levando ele a sentir o mesmo sentimento de traição.

Neste momento o participante apresenta uma nova informação por achar que era importante.

Outra coisa, eu não fumava e passei a fumar.

Rafael: O senhor sabe me dizer o porquê? Qual a sensação que traz para o senhor?

Parece que não tem o que fazer, sabe? É impotência!

R: Impotência com relação a sua esposa?

Isso! De não poder fazer nada. E também sexual.

R: AH. Perfeito. O senhor sente falta?

Sinto! Muita! 
A ênfase que Gustavo traz ao falar sobre as questões sexuais, demonstra que para além de uma prática significativa em sua vida, era algo que estava constantemente presente em sua relação conjugal, fazendo parte da sua dinâmica com dona Marilda.

Rafael: O senhor poderia falar um pouco mais sobre isso?

Posso... Antes da pandemia, eu tive casos pagos. Eu me masturbo.(...).Eu sinto muita falta. To meio sem jeito porque eu sou uma pessoa mais velha falando com uma pessoa mais nova.

Rafael: Compreensível. Essas relações pagas que o senhor comentou, encerraram durante a pandemia?

Sim, sim. Com a pandemia parou.

A necessidade de relações sexuais são enfatizadas aqui, entretanto o contexto pandêmico fez com que elas fossem cessadas, por ser uma atividade de extremo valor para ele é possível pensar que elas foram encerradas por conta da segurança de sua esposa, não a de si próprio.

R:E como o senhor se sente com essa situação?

É natural, o desejo é natural. É aquela necessidade animal mesmo.

R: Isso seria algo que não é supérfluo para o senhor? Seria algo necessário?

É bem necessário.

R: O cigarro substitui um pouco disso?

Substitui, substitui.

R: Me fala um pouco mais desta questão do cigarro. Como é que ele substitui e o que exatamente ele substitui?

É que às vezes eu tinha uns hábitos de... muito fetiche, de muita coisa. E às vezes eu esqueço e eu tenho dor escrotal. E se eu fico uns 45 dias sem fazer nada da dor escrotal. Então eu sinto uma necessidade fisiológica.

R: E o cigarro e a masturbação nutrem essa necessidade e aliviam a ponto de sanar a dor?

É, nutrem.

$R$ Entendi. 
Neste trecho, a fala do participante parece seguir um caminho distinto e até mesmo contraditório ao sentido subjetivo social do casamento que orienta a produção de uma percepção de traição. A maneira como ele subjetiva as suas relações sexuais ganham uma orientação de conduta distanciada de uma responsabilidade ou de uma moralidade ao ser produzida como puramente natural, à uma necessidade animalesca.

\section{CONSIDERAÇÕES FINAIS}

Neste trabalho o objetivo foi buscar compreender os diferentes processos da subjetividade social que são configurados em uma família que vive a dinâmica do cuidado de um parente que tem diagnóstico de Alzheimer. Tendo esse objetivo como orientação de produção, foi possível alcançar uma produção teórica a qual articula com os diversos fenômenos humanos e suas organizações. As produções aqui expostas não esgotam a discussão dos fenômenos relacionados às práticas do cuidado dentro de uma dinâmica familiar, e sim abrem margem para uma nova discussão a partir de uma nova inteligibilidade do fenômeno

Foi possível compreender como os sentidos subjetivos do diagnóstico foram produzidos na experiência dos cuidadores familiares. Diferentemente do caráter redutivo que o diagnóstico dentro de um modelo biomédico pode exercer no paciente diagnosticado, limitando as suas produções subjetivas às características associadas ao manual médico, como discutido por González Rey, 2017, a maneira a qual a pessoa com a função do cuidado produz a existência de um diagnóstico definido para seu parceiro(a) ocupa um espaço nas relações é extremamente positiva. Tendo em vista que as produções subjetivas são únicas e singulares a ausência de um diagnóstico para o cônjuge se configura de maneiras diversas, mas sempre sendo subjetivada de modo que o cuidador não ocupe a posição de sujeito, podendo também vivenciar uma experiência de sofrimento e adoecedora.

Tendo em vista que o diagnóstico dado em vida muitas requer um conjunto de sintomas, os quais podem demorar anos para satisfazer os critérios para um diagnóstico provável, sendo o diagnóstico conclusivo realizado apenas por meio de uma anatomopatológica após a morte do paciente. Esse período de ausência de um diagnóstico é longo, e quando realizado o diagnóstico as pessoas conseguem produzir um sentido a partir do diagnóstico. Essa 
produção estabelece uma real compreensão da condição de seus parceiros, passando a atuar de maneira mais ativa e segura ao se dedicarem na promoção do cuidado.

Dentro da dinâmica do cuidado realizado por parentes, se destaca a subjetividade social do casamento. A maneira como as dinâmicas do cuidado são intimamente vinculadas ao sentido do casamento, aparecendo como uma noção de dever e culpa. A subjetividade social do casamento constitui parte das configurações subjetivas das pessoas sendo uma orientação na produção de sentido subjetivos, que estão relacionados de modo tão íntimo ao cuidado que esta se torna a maior atividade na vida do cuidador, fazendo com que ele seja invisibilizado para si mesmo. A prática do cuidado demanda uma presença e uma atenção que falta para o próprio cuidador.

Como apontado por Delfino, Komatsu, Komatsu, Neri, Cachioni, 2021, a experiência do cuidador pode provocar transtornos psiquiátricos e alterações diversas que também apareceram. A hipótese construída através desta pesquisa é de que esse adoecimento está relacionado à configuração subjetiva do cuidado juntamente com o do casamento, no qual o cuidado do outro se torna a principal atividade e objetivo, buscando satisfazer as emocionalidades emergidas e objetivos configurados pelos sentidos subjetivos. Esta prática ocupa o espaço principal, no qual a pessoa abandona o próprio cuidado.

A formulação de um modelo teórico com relação ao tema abordado pela pesquisa se fez possível a partir da Teoria da Subjetividade, juntamente à sua metodologia construtivo-interpretativa, pois a partir de um processo dialógico e da criatividade determinadas experiências e as emocionalidades associadas a elas emergiram de modo que a subjetividade do participante fosse alcançada. A exposição da subjetividade da pessoa nos permitiu ter acesso a um conjunto de informações singulares e únicas para os participantes e por meio do método, articular as experiências subjetivas de modo que uma hipótese fosse construída. 


\section{REFERÊNCIAS}

Associação Brasileira de Psiquiatria., \& Asociación Psiquiátrica de América Latina. (1999). Revista brasileira de psiquiatria : publication of the Associação Brasileira de Psiquiatria - ABP, Asociación Psiquiátrica de la América Latina - APAL. Associação Brasileira de Psiquiatria.

Caramelli, P., \& Barbosa, M. T. (2002). Como diagnosticar as quatro causas mais freqüentes de demência? Revista Brasileira de Psiquiatria, 24(suppl 1), 7-10. https://doi.org/10.1590/S1516-44462002000500003

Charchat, H., Nitrini, R., Caramelli, P., \& Sameshima, K. (2001). Investigação de Marcadores Clínicos dos Estágios Iniciais da Doença de Alzheimer com Testes Neuropsicológicos Computadorizados. Psicologia: Reflexão e Crítica, 14(2), 305-316. https://doi.org/10.1590/S0102-79722001000200006

Delfino, L. L., Komatsu, R. S., Komatsu, C., Neri, A. L., \& Cachioni, M. (2021). Neuropsychiatric symptoms associated with family caregiver burden and depression. Dementia \& Neuropsychologia, 15, 128-135.

Espíndola, A. V., Quintana, A. M., Farias, C. P., München, M. A. B., Espíndola, A. V., Quintana, A. M., Farias, C. P., \& München, M. A. B. (2018). Relações familiares no contexto dos cuidados paliativos. Revista Bioética, 26(3), 371-377. https://doi.org/10.1590/1983-8042201826325

Falcão, D. V. da S., \& Bucher-Maluschke, J. S. N. F. (2008). Filhas que cuidam de pais/mães com provável/possível Doença de Alzheimer. Estudos de Psicologia (Natal), 13(3), 245-256. https://doi.org/10.1590/S1413-294X2008000300007

González Rey, F.(2003). Sujeito e subjetividade: uma aproximação histórica-cultural. Pioneira Thomson Learning, 2003.

González Rey, F. (2005). Pesquisa Qualitativa e Subjetividade. Thomnson Pioneira, 2005. 
González Rey, F., \& Mitjáns Matínez, A. (2017). Subjetividade: teoria, epistemologia e método.Campinas: Alínea, 2017.

Lima, T. M., Brandão, L., Parente, M. A. de M. P., Peña-Casanova, J., Lima, T. M., Brandão, L., Parente, M. A. de M. P., \& Peña-Casanova, J. (2014). Doença de alzheimer: cognição e discurso narrativo com apoio em figuras. Revista CEFAC, 16(4), 1168-1177. https://doi.org/10.1590/1982-021620147513

Martins, L. M., França, A. P. D., \& Kimura, M. (1996). Qualidade de vida de pessoas com doença crônica. Revista Latino-Americana de Enfermagem, 4(3), 5-18. https://doi.org/10.1590/S0104-11691996000300002

Mori, V. D., \& Rey, F. G. (2012). Psicologia: Teoria e Prática. In Psicologia: teoria e prática (Vol. 14, Issue 3). Universidade Presbiteriana Mackenzie. http://pepsic.bvsalud.org/scielo.php?script=sci_arttext\&pid=S1516-3687201200030001 $2 \& \operatorname{lng}=\mathrm{pt} \& \mathrm{nrm}=\mathrm{iso} \& \mathrm{t} \operatorname{lng}=\mathrm{pt}$

Schmidt, M. I., Duncan, B. B., Silva, G. A., Menezes, A. M., Monteiro, C. A., \& Barreto, S. M. (2011). Doenças crônicas não-transmissíveis no Brasil: carga e desafios atuais.

Rezende Garcia, L. P. R., \& de Oliveira Tavares, S. A. Mortalidade por doenças crônicas não-transmissíveis em Goiás, 2006 a 2016.

Saez-Atienzar, S., \& Masliah, E. (2020). Cellular senescence and Alzheimer disease: the egg and the chicken scenario. Nature Reviews Neuroscience. 


\title{
ANEXOS
}

\author{
Anexo A: Termo de Consentimento Livre e Esclarecido (TCLE) \\ Termo de Consentimento Livre e Esclarecido - TCLE \\ A experiência de ser cuidador de uma pessoa com Alzheimer: um estudo \\ com base na teoria da subjetividade
}

Instituição dos pesquisadores: Centro Universitário de Brasília - UniCEUB

Pesquisadora responsável: Valéria Deusdará Mori

Pesquisador assistente: Rafael Oliveira de Carvalho Mendes

Você está sendo convidado(a) a participar do projeto de pesquisa acima citado. 0 texto abaixo apresenta todas as informações necessárias sobre o que estamos fazendo. Sua colaboração neste estudo será de muita importância para nós, mas se desistir a qualquer momento, isso não lhe causará prejuízo.

O nome deste documento que você está lendo é Termo de Consentimento Livre e Esclarecido (TCLE).

Antes de decidir se deseja participar (de livre e espontânea vontade) você deverá ler e compreender todo o conteúdo. Ao final, caso decida participar, você será solicitado a assiná-lo e receberá uma cópia do mesmo.

Antes de assinar, faça perguntas sobre tudo o que não tiver entendido bem. A equipe deste estudo responderá às suas perguntas a qualquer momento (antes, durante e após o estudo).

Natureza e objetivos do estudo

O objetivo específico deste estudo é compreender como diferentes processos da subjetividade social da família se configuram na relação de cuidado com um parente com o diagnóstico de Alzheimer.

Você está sendo convidado a participar exatamente por exercer a função de cuidador(a) de um parente com o diagnóstico de Alzheimer.

Procedimentos do estudo

Sua participação consiste em participar de uma dinâmica conversacional com o pesquisador.

$\mathrm{O}(\mathrm{s})$ procedimento(s) serão realizados através de aplicativos de videoconferências de preferência do participante. Os horários serão decididos a partir da disponibilidade do mesmo. Serão realizados cinco (5) encontros de três (3) horas cada.

Não haverá nenhuma outra forma de envolvimento ou comprometimento neste estudo. 
A pesquisa será realizada em ambientes distintos entre o pesquisador e os(as) participantes por meio de aplicativos de videoconferência, sendo que os(as) participantes poderão escolher o ambiente o qual se sentem confortáveis para realizarem as chamadas.

Caso haja algum tipo de gravação, seja ela de vídeo e ou áudio, será solicitado ao participante previamente.

Riscos e benefícios

Este estudo possui riscos mínimos, podendo ter um desconforto por conta de entrar em contato com assuntos possivelmente delicados.

Medidas preventivas serão tomadas durante a pesquisa, sendo a pesquisadora chefe psicoterapeuta, orientando e oferecendo auxílio para minimizar qualquer risco ou incômodo.

Caso esse procedimento possa gerar algum tipo de constrangimento, você não precisa realizá-lo.

Com sua participação nesta pesquisa você poderá além de contribuir para maior conhecimento sobre a experiência de atuar como cuidador familiar de um parente com o diagnóstico de Alzheimer.

Participação, recusa e direito de ser e tirar do estudo

Sua participação é voluntária. Você não terá nenhum prejuízo se não quiser participar.

Você poderá se retirar desta pesquisa a qualquer momento, bastando para isso entrar em contato com um dos pesquisadores responsáveis.

Conforme previsto pelas normas brasileiras de pesquisa com a participação de seres humanos, você não receberá nenhum tipo de compensação financeira pela sua participação neste estudo.

Confidencialidade

Seus dados serão manuseados somente pelos pesquisadores e não será permitido o acesso a outras pessoas.

Os dados e instrumentos utilizados como filmagens e gravações de áudio, ficarão guardados sob a responsabilidade de Rafael Oliveira de Carvalho Mendes com a garantia de manutenção do sigilo e confidencialidade, e arquivados por um período de 5 anos; após esse tempo serão destruídos.

Os resultados deste trabalho poderão ser apresentados em encontros ou revistas científicas. Entretanto, ele mostrará apenas os resultados obtidos como um todo, sem revelar seu nome, instituição a qual pertence ou qualquer informação que esteja relacionada com sua privacidade.

Se houver alguma consideração ou dúvida referente aos aspectos éticos da pesquisa, entre em contato com o Comitê de Ética em Pesquisa do Centro Universitário de Brasília - CEP/UniCEUB, que aprovou esta pesquisa, pelo telefone 3966.1511 ou pelo e-mail cep.uniceub@uniceub.br. Também entre em contato para informar ocorrências irregulares ou danosas durante a sua participação no estudo.

\section{E-mail}


Nome completo

RG

Número do celular para contato via WhatsApp

Após receber uma explicação completa dos objetivos do estudo e dos procedimentos envolvidos, concordo voluntariamente em fazer parte deste estudo.

$\operatorname{sim}$ 